\title{
Jean-Claude Fignolé, Une heure pour l'éternité
}

\section{Luigia Pattano}

\section{(2) OpenEdition \\ Journals}

\section{Edizione digitale}

URL: http://journals.openedition.org/studifrancesi/8766

DOI: 10.4000/studifrancesi.8766

ISSN: 2421-5856

\section{Editore}

Rosenberg \& Sellier

\section{Edizione cartacea}

Data di pubblicazione: 1 décembre 2008

Paginazione: 714

ISSN: 0039-2944

\section{Notizia bibliografica digitale}

Luigia Pattano, «Jean-Claude Fignolé, Une heure pour l'éternité», Studi Francesi [Online], 156 (LII | III) | 2008, online dal 30 novembre 2015, consultato il 11 janvier 2021. URL: http://

journals.openedition.org/studifrancesi/8766 ; DOI: https://doi.org/10.4000/studifrancesi.8766

Questo documento è stato generato automaticamente il 11 janvier 2021.

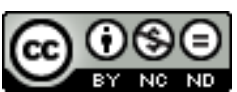

Studi Francesi è distribuita con Licenza Creative Commons Attribuzione - Non commerciale - Non opere derivate 4.0 Internazionale. 


\title{
Jean-Claude Fignolé, Une heure pour l'éternité
}

\author{
Luigia Pattano
}

\section{NOTIZIA}

JEAN-CLAUdE FIGNOLÉ, Une heure pour l'éternité, Paris, Sabine Weispieser, 2008, pp. 480.

1 Oggetto di grande interesse letterario e non solo, il passato glorioso di Haiti dalla cui rivoluzione è sorta la prima repubblica nera della storia si fa materia romanzesca nell'ultimo libro di Jean-Claude Fignolé. Con Une heure pour l'éternité non ci troviamo però di fronte a un romanzo storico convenzionale: se la storia, bistrattata da coloro che più hanno contribuito a determinarla (per Pauline Bonaparte, al pari della politica, essa non è che «un magnifique mais trop souvent sordide jeu d'illusions» p. 187), occupa una posizione centrale nel testo, altrettanta importanza riveste la dimensione psicologica ed esistenziale dei personaggi. Tre voci si alternano in lunghi monologhi e dialoghi fittizi al capezzale dell'agonizzante Victor-Emmanuel Leclerc: quella a tratti lucida a tratti allucinata del generale stesso, quella della moglie Pauline, sorella di Napoleone Bonaparte, e quella della serva Oriana.

Inviato (o meglio allontanato) nel 1802 per sedare la rivolta di Toussaint Louverture e reintrodurre la schiavitù a Saint-Domingue dal potentissimo cognato, Leclerc sta per morire in preda alle allucinazioni provocate dalla febbre gialla. Convinto di trovarsi di fronte l'acerrimo nemico sconfitto, trascorre la sua ultima ora di vita in un dialogo immaginario con quell'uomo che disprezza ma per cui nutre al tempo stesso una profonda ammirazione. Quello che inizia come un litigio tra un inflessibile Leclerc e un Toussaint Louverture abile retore diventa a poco a poco un'amabile conversazione tra compagni d'armi che si rispettano nonostante antichi dissapori.

3 Attorno al moribondo, un gruppo di persone ne attende la morte con pacata indifferenza. Pauline, dipinta all'inizio con sguardo severissimo da Oriana, è una donna dai costumi a dir poco disinvolti, la cui importanza capitale nella colonia risiede, agli 
occhi dello stesso marito, nel risollevare il morale dei soldati cui si concede facilmente. Questa eroina flaubertiana che cerca incessantemente di rifuggire la noia svolazzando «d'homme en homme, d'un désir inassouvi à un besoin non satisfait» (p. 63), e che si muove costantemente inappagata tra due scogli («celle que j'étais, celle que je voulais être» p. 64) non manca certo, al pari di Emma Bovary, di spessore e di intelligenza. Da lei Oriana ha appreso «que la nature humaine est une. La différence entre les hommes, couleur, race, n'est qu'affaire de perception» (p. 107). È nel suo letto che Pauline ottiene informazioni sulle torture che il marito ordina (o perlomeno tollera) e che si decidono le sorti dell'isola. Abbandonata dal fratello e "prise au piège de l'histoire. Au surplus piégée par sa propre histoire», Pauline si erge a difensore dei diritti dell'uomo negando il letto al marito a causa delle atrocità di cui si macchia e informando il suo amato Pétion, «nègre doré» e unico uomo in grado di appagare il suo desiderio d'amore.

Il racconto, che si basa su una documentazione storica molto rigorosa, è servito da una prosa classica di ampio respiro che ne rende avvincente la lettura. 